\title{
A IDENTIDADE DO CURSO DE PEDAGOGIA: UMA INVESTIGAÇÃO VIA HISTÓRIA ORAL
}

Vanessa Ananias Malacrida, Fabiana Gonçalves Monti, Helena Faria de Barros, Adriano Rodrigues Ruiz

Mestrado em Educação da Universidade do Oeste Paulista - UNOESTE. E-mail: vamalacrida@bol.com.br

\section{RESUMO}

Este artigo resulta da pesquisa vinculada a CAPES por meio do Programa PROSUP cujo objetivo foi investigar como ex-docentes e professores atuais do curso de Pedagogia compreendem a formação da identidade profissional do pedagogo. Os participantes da pesquisa foram sete docentes sendo quatro atuais e três ex-docentes que iniciaram sua docência no curso de pedagogia por volta da década de 1970 nos cursos de pedagogia da Universidade Estadual Paulista FCT - UNESP e a Universidade do Oeste Paulista- UNOESTE. A metodologia utilizada foi a História Oral com entrevista Temática e abordagem "narrativo-narrativa" conforme GARNICA, (2008). Os resultados da pesquisa mostram que a identidade do curso de pedagogia antes voltada à formação do técnico, hoje visa-se a formação do professor polivalente. Segundo um dos entrevistados "o pedagogo estuda de tudo, mas não é especialista em nada", e conforme assevera Chakur, a identidade apresenta-se fragmentada e sem delimitação.

Palavras-chave: Identidade do curso; Formação do pedagogo; História oral; Pedagogia; Professor.

\section{INTRODUÇÃO E OBJETIVOS}

Considerando a importância da formação da identidade do professor e o contexto atual que envolve novos desafios devido às mudanças sócio-culturais em que a identidade do professor vem sendo questionada é preciso ter claro o papel do professor que se quer formar. Nesta pesquisa por meio da história oral realizou-se uma comparação com a formação da identidade docente buscada pelos cursos de pedagogia no passado e no presente.

Nossa identidade de professor é como nos enxergamos no exercício docente, constituindo-se em motor da caminhada educativa a ser desenvolvida. Dada a importância da identidade para o exercício docente, a construção da identidade docente precisa ser objeto de intencionalidade educativa, ganhando significância como tema de pesquisa e espaço de reflexão especialmente na formação inicial dos professores, consciente da crise de identidade da profissão docente este tema é de grande relevância.

A pesquisa a qual se refere este artigo propôs por meio da história oral, uma comparação com a formação da identidade docente buscada pelos cursos de pedagogia no passado e no presente. Essa pesquisa contou com a participação de pessoas que trazem grande riqueza em sua colaboração por meio de seus depoimentos, "os ex- docentes por meio de suas 
lembranças e a visão dos atuais", possibilitaram um contraponto entre o passado e o presente, cujos depoimentos são importante fontes de estudo e trazer à tona a memória da identidade buscada pelos cursos de pedagogia há algumas décadas passadas será de grande valor para perceber se houveram mudanças ou não, nos cursos de pedagogia ao longo deste período neste sentido e as possíveis adequações realizadas de acordo com as vicissitudes da legislação e das mudanças sociais atuais. Neste artigo são apresentados resultados parciais da pesquisa que foi realizada em 2011 e 2012 por um grupo vinculado ao PROSUP - CAPES.

\section{METODOLOGIA}

A pesquisa foi aprovada pelo Comitê de Ética na Pesquisa sob o protocolo $\mathrm{n}^{\circ}$ 1032. Adotamos como modelo de investigação a pesquisa qualitativa com enfoque fenomenológico hermenêutico na modalidade História Oral com entrevista Temática. A investigação teve abordagem "narrativo-narrativa" conforme GARNICA, (2008, p.117). Os participantes da pesquisa foram quatro docentes que atuam há mais de 10 anos e menos que 15 anos e três ex-docentes que iniciaram sua docência no curso de pedagogia na década de 1970, ou antes. Sendo assim, participaram da pesquisa, docentes de dois cursos de Pedagogia de Presidente Prudente que funcionam há mais de trinta anos, ou seja, os cursos de pedagogia da Universidade Estadual Paulista "Julio Mesquita Filho", a FCT- UNESP e a Universidade do Oeste Paulista- UNOESTE.

\section{SOBRE OS CURSOS INVESTIGADOS}

A cidade de Presidente Prudente conta atualmente com 3 cursos de pedagogia. De acordo com o critério de escolha mencionado no projeto de pesquisa os cursos estudados deveriam ter mais de 30 anos de funcionamento é um curso recente, que não atende esse critério assim sendo, foram selecionados para investigação nesta pesquisa apenas os dois cursos mais antigos, os participantes da pesquisa são os docentes da Universidade do Oeste PaulistaUNOESTE e da Universidade Estadual Paulista- FCT/ UNESP.

A UNESP-FCT -Faculdade de ciências e tecnologia Presidente Prudente tem em torno de 3.000 alunos de graduação e 345 de pós-graduação. Possui 12 cursos de graduação além de cursos de pós-graduação lato sensu, cursos de mestrado e doutorado. A Universidade do Oeste Paulista conta atualmente com aproximadamente 12 mil alunos, 53 cursos presenciais de graduação, mais de 100 cursos presenciais de especialização além de cursos de mestrado. 
Quando o Professor 1 começou lecionar no curso de Pedagogia da UNESP em Presidente Prudente, a partir de 1964, era um curso recém-criado em um instituto isolado do Ensino Superior do Estado. "O curso de Pedagogia começou pequeno e foi crescendo e também foi mudando. A partir de 1965, os institutos isolados passaram a ser a Universidade Estadual PaulistaUNESP" (PROFESSOR1).

Sobre a história da Pedagogia da UNESP "eu sei que o curso aqui foi criado em 57 e começou a funcionar em 1959, em 1976, houve a fusão dos Institutos Isolados da USP e criou-se a UNESP. O curso de Pedagogia nessa nova versão começou a funcionar em 89. E a gente ficou de 76 até 89 sem funcionar e teve a primeira turma em 89 depois seguiu até agora, passou por algumas reformas. (PROFESSOR 5)

O Professor 2 começou a lecionar no ensino superior em 1973 na Unoeste por convite e lecionava no Instituto Municipal, incorporado à Unesp, lecionou entre 1973 e 1996 "quando a UNESP incorporou o Instituto Municipal passei também a fazer parte do corpo docente desta universidade, isso foi mais ou menos em 1973".

O Professor 4 diz que:

"Sobre a história do curso da Unesp eu sei que o curso teve dois começos, porque ele fez parte, em um primeiro momento, de um Instituto Isolado e, quando a Unesp foi fundada, esse curso tinha sofrido um corte em função da ditadura. Eu não participei desse curso inicial que se extinguiu, esse segundo curso de Pedagogia, que é esse que temos até hoje, eu sou dessa leva que entrou em 1992".

No processo de organização da UNESP foram extintos e remanejados vários cursos, principalmente os das áreas de Letras, Filosofia, História e Educação, sob alegação de racionalidade administrativa e necessidade de não duplicar meios para os mesmos fins. Apesar de manifestações contrárias da comunidade acadêmica e de setores da sociedade civil, "então foi quando o curso de Pedagogia também foi reformulado, extinto na FCT de Presidente Prudente e transferido para Marília, a cidade escolhida no oeste paulista" de acordo com o professor 1:

"O motivo da extinção apresentado é de que havia excesso de cursos na UNESP. Então, era para fazer um curso, um tipo de curso no leste de São Paulo e um tipo de curso no oeste de São Paulo, então no oeste de São Paulo ficou Marília e assim foi com todos os cursos. Era a ideia do reitor, ideia do governador... então houve essa redução de cursos e depois voltaram e foram empilhados outros (...) Depois, quando voltou a Pedagogia, voltou com nova estruturação e o objetivo já foi a formação do professor, como sendo essencial, eu já tinha saído, já tinha aposentado, mas os professores que reestruturaram o curso já pensavam na 
importância da formação do professor e reestruturar o novo curso de Pedagogia com formação de professores. (PROFESSOR1)

Sobre a história do curso de pedagogia da UNOESTE o Professor 6 disse que:

A história do curso da UNOESTE já tem trinta e cinco, trinta e seis anos. Eu não tomei parte nessa história desde o início, mas eu sei que foi o professor Agripino, que ainda é o mantenedor e com um grupo de amigos, eles começaram a faculdade. O interessante é que começou com a FACLEPP, essa faculdade de Filosofia, Ciências e Letras e depois foi se espalhando, foi aumentando e o braço direito sempre a dona Ana que é esposa, foi esposa do professor Agripino. E aí é essa potência que é hoje.

\section{PEDAGOGIA E FORMAÇÃO DE PROFESSORES}

Ao longo da história da civilização ocidental a pedagogia desenvolveu-se segundo Saviani $(2008$, p.1) em intima relação com a prática educativa "constituindo-se como teoria ou ciência dessa prática sendo, em determinados contextos, identificada com o próprio modo intencional de realizar educação".

O termo pedagogia surgiu na Grécia e segundo Saviani desde a Grécia delineouse uma dupla referencia para o conceito de pedagogia sendo de um lado uma reflexão ligada à filosofia voltada à finalidade ética que guia a atividade educativa e do outro lado mais voltada ao sentido etimológico da pedagogia como a condução da criança "no sentido empírico e prático inerente a paidéia entendida como a formação da criança para a vida" (SAVIANI, 2008, p.2).

A formação do pedagogo brasileiro hoje, na visão do professor 1 :

"O curso de Pedagogia mudou. Hoje tem que formar o professor de Educação Infantil, de Educação Fundamental e o Gestor, então essa é a função do professor, é trabalhar com a escola, trabalhar com o Ensino Fundamental. Hoje, eu acho que o ideal seria a reflexão sobre a prática, então um professor deve aprender a ser investigador da própria prática; mas, quando eu comecei, era lecionar durante muito tempo. Acreditava-se e trabalhava no sentido que ele tivesse o conteúdo científico, supondo que a partir daí ele trabalharia bem na sua prática. Houve mudança de concepção, quer dizer, é da lógica técnica para a lógica reflexiva que houve a mudança. $O$ curso de Pedagogia para formar o professor polivalente é uma conquista atual, não é... quer dizer, a preocupação do curso de Pedagogia sempre foi a formação do técnico e, mesmo quando deixou de ser bacharelado para ser, em 62, também licenciatura, a preocupação era pouca com a docência, a preocupação era com a formação do técnico, só hoje, recentemente, que a grande preocupação é formar o docente."

o professor 2 começou a lecionar no ensino superior em 1973 na Unoeste

lecionava também no Instituto Municipal que foi incorporada à Unesp segundo ele: 
"o perfil do profissional pedagogo era mais centrado na formação de professor do que no próprio gestor nos cursos normais de pedagogia, muito mais com embasamento teórico do que exatamente embasamento prático. Eu acho que a universidade deveria conciliar as duas coisas, tanto a prática quanto a reflexão teórica, claro que temos todo um embasamento teórico necessário e uma aplicação prática para que ele possa realmente acompanhar e vivenciar essa prática dentro da comunidade. Hoje nós não podemos pensar mais na universidade sem prática, inclusive comunitária."

Para o professor 4 ainda é preciso algumas mudanças:

"o pedagogo brasileiro ele ainda está naquela linha que eu acho que tem que ser mudada, que ele ainda não conseguiu ser educador, ele não conseguiu ainda sentir que ele tem que trabalhar com o aluno essa questão da autonomia do aluno ser brasileiro, a identidade que ele tem que ter enquanto sujeito, eu acho que ainda existem muitos cursos de Pedagogia em que a preocupação é o conteúdo.hoje a ênfase não é mais na Psicologia, a ênfase é na Gestão tanto que eu acho que a gente tem muito mais disciplina de Gestão (até algumas desnecessárias, que podiam ser fundidas).Das relações que se estabelece da Pesquisa com a Extensão, então, a Universidade Pública tem essa vantagem, ele é quase que obrigado a fazer isso. Como a gente tem um regime de educação exclusivo, nós ficamos 40 horas aqui, Então hoje a Universidade nos exige produção acadêmica e para você produzir artigos, você tem que fazer Pesquisa".

O Professor 5 comenta a importância da teoria:

A gente tem, às vezes, até fama de que na UNESP a gente ensina muita teoria e pouca prática, para mim é até equivocada, na minha opinião, o que a gente não consegue fazer aqui é síntese, fazer sínteses eu acho que no curso temos dificuldade de fazer essa síntese e isso se reflete na sala de aula, então fica aquela coisa meio assim, me ensinam teoria lá, mas prática nenhuma, quer dizer é uma situação que o aluno revê, depois de dois ou três anos de exercício, ele percebe então, tem muita coisa que eu aprendi na UNESP que para mim é útil.

\section{A IDENTIDADE PROFISSIONAL}

A identidade profissional do docente exige formação inicial e continuada. Principalmente a formação inicial deve ser proposta na base da reflexão, inovação e investigação, de modo que aprenda e desenvolva mais competências cognitivas do que competências técnicas. Conforme Pacheco (1995, p. 61) "embora existam ferramentas básicas - habilidades, técnicas, conhecimentos, atitudes - que se espera que o professor domine, sugere-se, no entanto, como principal competência a tomada de decisões e a resolução de problemas profissionais". 
Uma identidade profissional pouco consistente surge como lacuna que dificulta passos mais autônomos do professor, isso em boa parte é devido a uma tardia tomada de consciência de que ensinar não se restringe ao domínio da prática. Roldão (2007) argumenta que:

A actividade de ensinar - como sucedeu com outras actividades profissionais - praticou-se muito antes de sobre ela se produzir conhecimento sistematizado. Estas profissões transportam por isso uma inevitável "praticidade" que, a não ser questionada/teorizada, jamais transformaria a actividade em acção profissional e mantê-la-ia prisioneira de rotinas não questionadas e incapazes de responder à realidade. Todavia, a progressiva teorização da acção, neste como noutros domínios, foi gerando, por sua vez, novos corpos de conhecimento, que passam a alimentar - e a transformar - a forma de agir dos profissionais em causa.

Para o professor 2 o pedagogo é aquele que consegue coordenar as ações não só de professor, de como também fazer a parte toda de orientação "metodológica, orientação administrativa, essa seria a figura do pedagogo hoje em termos de pedagogia escolar. Hoje nós estamos com o pedagogo também em empresas onde se trabalha com adolescentes, famílias, quer dizer, aquele que vai facilitar a aprendizagem, vai conduzir".

Para o professor 3 quem forma o professor são os cursos de pedagogia, mas:

Eu não tenho certeza, mas acho que a formação em Gestão não ocupa os 50 \% e muito menos ela perpassa o curso de Pedagogia essa formação de gestor precisa ser completada com um curso de especialização, mestrados em Educação, que realmente contêm uma formação na área da Gestão.

Quando fui aluna da UNESP por volta dos anos 70, "o foco não era ainda nem pesquisa nem extensão porque isso veio depoi, o embasamento teórico era grande, pesado e quem tinha como eu tive a possibilidade de estar concomitantemente exercendo magistério podia conciliar as duas coisas, quem tinha não ficava mais na teoria. Com a primeira $L D B$, com a primeira reforma universitária surgiu essa preocupação com a pesquisa principalmente aliada à docência. Na época que fiz pedagogia nós tínhamos muito pouco sobre Pesquisa Científica, nós fazíamos muito mais pesquisa do livro, resumo, nós chegávamos na aula e discutíamos, nós não tínhamos essa exigência de pesquisa científica, não que não houvesse, mas não predominava. Hoje a gente já percebe que existe uma preocupação grande com a pesquisa, antes não havia muito a preocupação com a Extensão, a Pesquisa. Os professores já estavam ali desenvolvendo a pesquisa, mas com a comunidade era bastante tímida, diferente de hoje. A Universidade hoje tem um compromisso, ela é muito aberta em questão da responsabilidade social, ambiental, muito voltada para comunidade;

Sobre o perfil do profissional pedagogo que o curso pretendia formar, "pela Legislação e pela sua Constituição era para formar o técnico em Educação, então no começo tinha 
só bacharelado e depois, a partir de 62, as pessoas que tivessem terminado o bacharelado, iria completar com um ano de licenciatura". Conforme o professor 1:

A formação de professor vinha atravessada porque o curso de Pedagogia tinha a preocupação de formar o técnico em Educação, mas eles procuravam o curso procurando ser professores, então a formação de professores era atravessada. Em 1996 que mudou a formação. A formação do pedagogo brasileiro hoje, ou pelo menos o curso de Pedagogia, mudou. Hoje tem que formar o professor de Educação Infantil, de Educação Fundamental e o Gestor.

O professor 3 comenta que a Pedagogia,

"enquanto formadora de professor da Educação Infantil e das Séries Iniciais do Ensino Fundamental, entendo que deve oferecer competências direcionadas de Gestão Democrática Escolar, principalmente ela tem que ser complementada porque a Pedagogia não dá conta dessa formação toda. São três mil e duzentas horas, é um tempo bem insuficiente e sem considerar que a Educação é a base de tudo: de um progresso, de um país... Então a Pedagogia ela tem que tomar conta disso tudo, não estou falando das outras licenciaturas, porque elas são específicas. (nos teríamos que dar as aulas práticas para que pudesse ter a nota dentro da metodologia e da didática, ela era avaliada na prática vamos dizer assim, e isso foi mais próximo do que o curso superior, meu curso superior foi é muito baseado na teoria e no conhecimento dos grandes autores e dos grandes filósofos, tive uma excelente formação, mas realmente em termos de sala de aula muito mais teórica do que prática". Antes não se tinha a preocupação na contratação de professores para a Pedagogia, agora está tendo. Porque se ele tem uma prática de primeira à quarta o trabalho dele na Universidade é diferente.

\section{ALGUMAS CONSIDERAÇÕES}

Analisando os relatos dos professores percebe-se que consideram importante na formação do pedagogo de hoje a reflexão sobre a prática, então "um professor deve aprender a ser investigador da própria prática"; mas, antigamente "acreditava-se e trabalhava no sentido que ele tivesse o conteúdo científico, supondo que a partir daí ele trabalharia bem na sua prática" de acordo com o professor 1 "houve mudança de concepção, quer dizer, é da lógica técnica para a lógica reflexiva".

Aparece também a preocupação com a articulação teoria e prática e a responsabilidade social da universidade "Eu acho que a universidade deveria conciliar as duas coisas, tanto a prática quanto a reflexão teórica, hoje nós não podemos pensar mais na universidade sem prática, inclusive comunitária". (PROFESSOR 2). 
"Porque se eu der o modelo pronto, que vem nas revistas, ela nunca vai aprender a usar outros exercícios. Então, educação pra mim é isso, é saber aplicar na prática aquela teoria aprendida e mudar o seu entorno, é buscar sempre progredir, sempre fazer o melhor." (PROFESSOR 6) (Após um longo discurso sobre como trabalha teoria e prática com seus alunos do curso de pedagogia.)

Os docentes consideram ainda que o curso no Brasil não atingiu as mudanças necessárias:

"o pedagogo brasileiro ele ainda está naquela linha que eu acho que tem que ser mudada, que ele ainda não conseguiu ser educador, ele não conseguiu ainda sentir que ele tem que trabalhar com o aluno essa questão da autonomia do aluno ser brasileiro, a identidade que ele tem que ter enquanto sujeito, eu acho que ainda existem muitos cursos de Pedagogia em que a preocupação é o conteúdo. Eu, por exemplo, fui avaliadora do INEP muitos anos, de 2000 a 2009, e fui a muitas faculdades particulares no Brasil avaliando o conteúdo, avaliando as metodologias as práticas e aí nas práticas você via que os livros estão na biblioteca, as bibliotecas bonitas porque exige-se que tenha cinco, dez volumes duma mesma edição, bibliotecas melhores que as nossas aqui, mas que na prática pedagógica, ou seja, no dia a dia da sala de aula não chega e ainda há professores que dizem com todas as letras: "Olha, meu objetivo é passar a matéria, se ele está a fim ou não, problema dele...". Mas não é isso, o problema dele é o seu problema. Ainda acho que no Brasil precisa-se um bom trabalho de formação para mudar essa concepção, e quando eu digo de formação, eu estou dizendo das diferentes IES, educação de Ensino Superior.

Um fato claro nos depoimentos é que os cursos antes técnicos hoje são mais voltados para a formação do professor reflexivo, a pesquisa e a extensão é muito mais valorizada hoje, há a preocupação com o papel social da universidade, porém o que existe é um problema sério de identidade, conforme o Professor 5:

Só que é o seguinte, o curso de Pedagogia tem um problema sério de identidade, porque ele pode formar o generalista e o especialista, então tem um problema sério de identidade, não existe uma ciência da educação, porque em minha opinião não existe, agora você tem vários conteúdos aplicados, por exemplo, o pedagogo tem que ter uma boa noção de Sociologia, de Filosofia, de História, de Psicologia, isso acaba desidentificando o pedagogo porque ele acaba sendo, em um dos momentos tudo, e não é nada, porque não é um especialista em Psicologia, não é especialista em Sociologia e o mais difícil é você discutir isso com os pedagogos, há uma necessidade muito grande de dizer que Pedagogia é Ciência, não sei o porquê, enquadrar as Ciências Sociais em Geral, em parâmetros a ciência que nós conhecemos é meio complicado, mas é difícil você discutir isso, eu já tive alguns embates em encontros por conta disso. 


\section{CONCLUSÃO}

Conclui-se, portanto que apesar de todas mudanças que envolveram os cursos de pedagogia, inclusive as legislativas, ainda há neste curso um problema sério de identidade que precisa ser estudada, pensada e redefinida uma vez que, exige uma ampla abrangência de conhecimentos em diversas áreas, mas não pode dar conta completamente de todas.

Um curso que definido por lei forma o professor polivalente, o que já engloba muitos conteúdos curriculares diferentes, porém, tem ainda, a preocupação com a gestão, as disciplinas específicas do ensino fundamental, a inclusão, as especificidades do nível de educação infantil e do fundamental, que são diferentes, também tem a importância que é dada a pesquisa de iniciação cientifica característica do ensino superior, será possível atender tudo isso com qualidade? E então? Qual a identidade do pedagogo? Pesquisador? Gestor? Professor de educação infantil? Professor de ensino fundamental? Professor de quê? Professor de português? De Matemática? De ciências? De geografia? De educação especial?

Entendemos que talvez a maior necessidade de mudança não seja no currículo, mas na legislação, o pedagogo tem que estudar tudo que engloba a educação para sair com o titulo de professor das séries iniciais do ensino fundamental e educação infantil, se ele estuda gestão porque o diploma é só de professor? E se ele é só professor por que estudar gestão? Percebe o problema de identidade? Até quando os alunos de pedagogia terá que ficar retornando a universidade para fazer pós-graduação referente a temas que estudou na graduação, mas que não tem no seu diploma e precisa do titulo para o emprego, ou até quando o professor terá que voltar para a universidade porque o curso que era abrangente demais não deu conta da formação necessária em uma determinada área de atuação? São apenas reflexões que demonstram a necessidade da definição da identidade do pedagogo na legislação nacional.

\section{REFERÊNCIAS}

ADORNO, T. Educação e emancipação. Rio de Janeiro: Paz e Terra, 1995.

CHAKUR, C. R. S. L. A profissionalidade docente em uma abordagem construtivista. Cadernos de Pesquisa, no.117, São Paulo, 2002. Disponível em: <www.search.scielo.org/?q=A profissionalidade docente \&where=ORG>. Acesso em 05 out. 2010.

GARNICA, A.V. M. A experiência do labirinto. São Paulo: Unesp, 2008.

PACHECO, J. A. O pensamento e a ação do professor. Porto: Porto Editora, 1995. 
ROLDÃO, M. C. Função docente: natureza e construção do conhecimento profissional. Revista Brasileira de Educação, v.12, no. 34, Rio de Janeiro, jan./apr. 2007.Disponível em: $<$ www.scielo.br/scielo.php?script=sci arttext>. Acesso em 05 out. 2010.

SAVIANI, D. Pedagogia e formação de professores no Brasil: vicissitudes dois últimos séculos. UNICAMP. Disponível em: http://www.sbhe.org.br Acesso em: 27/05/2011. 